\title{
Disaster Information Extraction from ALOS Images
}

\author{
By Tamotsu IGARASHI ${ }^{1)}$, Ryoichi FURUTA ${ }^{2)}$ and Makoto ONO $^{2)}$ \\ ${ }^{1)}$ Earth Observation Research Center (EORC) Japan Aerospace Exploration Agency (JAXA), Tsukuba, Japan \\ ${ }^{2)}$ Remote Sensing Technology Center of Japan (RESTEC), Tokyo, Japan
}

(Received April 24th, 2008)

\begin{abstract}
ALOS is a satellite for land observation with high spatial resolution and wide field of view, providing time series image data sets revealing the land-use and land-cover change. The earth surface is changing due to many dynamics by natural phenomena or events as well as human-induced developments. ALOS is a unique satellite system dedicated to the observation of land-cover dynamics, enabled by the sensor suite composed of PRISM, PALSAR and AVNIR-2 onboard satellite system operated with the interruptible systematic observation strategy, to detect and track disasters. This paper describes the ALOS data applicability with the expected future improvement to fill the gap between the present state of the arts and the ideal performance in the early case studies toward the operational disasters management.
\end{abstract}

Key Words: ALOS, Land-Use Land-Cover, Monitoring

\section{Introduction}

Satellite-based Earth Observation in the past three decades, beginning as the Landsat data applications program by National Space Development Agency of Japan (NASDA) in Japan from 1978, through the initiative in Research and Development (R\&D) on space applications technology, exploration and demonstration of the applicability of satellite-based disaster monitoring, had acquired informative measurement data of disasters (Kishi et al., 1986') at every occasion.

In the history of earth observation application programs in Japan developing and operating satellites/sensors; Marine Observation Satellite-1, -1b (MOS-1, -1b or Momo)/Multispectral Electronic Self-Scanning Radiometer (MESSR), Visible and Themal Infrared Radiometer (VTIR), Microwave Scanning Radiometer (MSR) (1987-96), Japanese Earth Resources Satellite-1 (JERS-1 or Fuyo)/Optical Sensor (OPS), Syntetic Aperture Radar (SAR) (1992-98), Advanced Earth Observing Satellite (ADEOS or Midori)/Advanced Visible and Near Infrared Radiometer (AVNIR), Ocean Color and Temperature Scanner (OCTS) (1996-97), Tropical Rainfall Measuring Mission (TRMM)/Precipitation Radar (PR) (1997-), Earth Observing System (EOS)-Terra/Advanced Spaceborne Thermal Emission and Reflection radiometer (ASTER) (1999-), EOS-Aqua/Advanced Microwave Scanning Radiometer for EOS (AMSR-E) (2002-) and ADEOS-II (or Midori-II)/Global Imager (GLI), AMSR (2002-03), the observation data had indicated that they had innovative and promising potential to provide practically useful information to derive the first assessment of order of magnitude and damages on the eruption of Mt. Pinatubo in 1991, the Great Hansin-Awaji Earthquake in 1995,
Nakhodka Oil Spill in 1997, the heavy rainfall in Tokai Japan in 2000, and the forest fires in Siberia in 2003. They were an instance of many events to prove the significance of remote sensing from space.

The disaster information have been derived from remotely sensed data from space which could cover wide damaged area in one observation, and the information extracted from image data were distributed to the authorities for the local disaster mitigation and management and to the public.

With the passage of time, the number of disasters is increasing. However we suffer a great loss from geo-hazard such as earthquakes and volcanic eruptions, most of disasters are derived from hazardous weather sometimes attributed to the climate change, such as heavy rainfalls, floods, wind-fallen trees, wild fires, forest fires and heat waves, etc..

Therefore, the International Council for Science (ICSU) is developing a program of research aimed at strengthening international science to provide a firmer basis for policies to prevent natural hazards from coming disasters (Rattakul'), Gupta ${ }^{3)}$, 2007). In 2008, as a report of ICSU planning group on natural human-induced environmental hazards and disasters, a research plan was issued $^{4)}$.

Advanced Land Observing Satellite (ALOS or Daich) developed dedicated to the global disaster monitoring as one of its missions is in operation from the launch in 2006. During two years after launch, it is piling up repertory of data to demonstrate applicability for disaster monitoring and providing data sets available for the preparedness against the coming disasters as concerned in the world. 


\section{Ingenious System for Disaster Observation}

In the R\&D phase of ALOS (Osawa et al..$^{5)}$ ), new ideas were integrated in the earth observation satellite system (Table 1) and satellite-borne remote sensors (Table 2) to firm the disaster observation and to foresee the vulnerability to disasters and precursory events of coming disaster in process.

Although the mission objectives are primarily focused on the following five themes;

1) Disaster Observation,

2) Regional Observation,

3) Cartography,

4) Resources Exploration and

5) R\&D for Earth Observation Satellites.

The disaster observation comprehends all of other themes, because the required functions and performances for disaster observation satellite system are almost superior to other mission and commonly usable for high resolution satellite applications.

To realize the compatibility of these multiple mission objectives, the prioritized observation strategy was developed for operating with the interruptible systematic observation for the regional geographic mapping required for cartography, forest mapping or environmental issues, with the emergency observation of concerned area in contingency planning for disasters.

ALOS is a satellite enabling imaging the fine structures and the topographic features on Earth with high resolution of $2.5 \mathrm{~m}$ to $100 \mathrm{~m}$, and wide field of view of $35 \mathrm{~km}$ to $350 \mathrm{~km}$, providing time series image data sets revealing the land-use and land-cover change.

Among many dynamics on Earth, disasters are induced by natural phenomena or events such as volcanic activity, landslide due to the earthquake or heavy rainfall, flood disaster as well as human-induced developments.

The recurrent cycle of ALOS is 46 days in the observation by Advanced Visible and Near Infrared Radiometer type 2 (AVNIR-2), Phased Array type L-band Synthetic Aperture Radar (PALSAR) and Panchromatic Remote-sensing Instrument for Stereo Mapping (PRISM) with $70 \mathrm{~km}$ wide nadir viewing observation mode, and 92 days by PRISM Three Line Scanner (TLS) mode observation with $35 \mathrm{~km}$ wide viewing, therefore ALOS data sets are suitable for the systematic mapping of the land surface to detect and track disasters.

Sensor specification of three sensors; PRISM, PALSAR, and AVNIR-2 have been determined in trade-off study within restraint condition of resources to accommodate requirements, in a sense of system engineering. Therefore, however they have not necessarily the ideal specification individually, they are mean to be integrated into one sensor suite onboard one platform to perform complementally.

The newly developed technologies for earth observation satellite system and sub-system dedicated to the ALOS mission are followings.

1) Rigid platform supporting sensors to minimize the thermal distortion for the precise pointing of PRISM
Table 1. Primary characteristics of ALOS system.

\begin{tabular}{|c|c|}
\hline Item & Characteristics \\
\hline Launch and Operation & $\begin{array}{l}\text { Launch: by H-IIA F8 with } 5 \mathrm{~m} \\
\text { faring on January } 24,2006 \text { from } \\
\text { TNSC } \\
\text { Operation life time: } 3-5 \text { years }\end{array}$ \\
\hline Orbit & $\begin{array}{l}\text { Sun-synchronous sub-recurrent } \\
\text { orbit: } \\
\text { - Altitude: } 691.65 \mathrm{~km} \\
\text { - Inclination: } 98.16 \mathrm{deg} \text {. } \\
\text { - Period: } 98.7 \mathrm{~min} \\
\text { - Local sun time of descending } \\
\text { node: } 10: 30 \pm 15 \text { min a.m. } \\
\text { - Recurrent cycle: } 46 \text { days } \\
\text { - Repetition accuracy: } \pm 2.5 \mathrm{~km} \\
\text { on equator }\end{array}$ \\
\hline Attitude & \\
\hline - Pointing Stability & $\begin{array}{l}\text { Short period: } \\
2.0 \times 10^{-5} \mathrm{deg} \mathrm{p}-\mathrm{p} / 0.37 \mathrm{~ms}(\mathrm{R} / \mathrm{Y}) \\
1.0 \times 10^{-5} \mathrm{deg} \mathrm{p}-\mathrm{p} / 0.37 \mathrm{~ms}(\mathrm{P}) \\
\text { Medium period : }\end{array}$ \\
\hline DRC* off & $2.0 \times 10^{-4} \mathrm{deg} \mathrm{p}-\mathrm{p} / 1 \mathrm{~s}(\mathrm{R} / \mathrm{P} / \mathrm{Y})$ \\
\hline DRC on & $\begin{array}{l}4.0 \times 10^{-4} \mathrm{deg} \mathrm{p}-\mathrm{p} / 1 \mathrm{~s}(\mathrm{R} / \mathrm{P} / \mathrm{Y}) \\
\text { Long period: }\end{array}$ \\
\hline DRC off & $2.0 \times 10^{-4} \mathrm{deg} \mathrm{p}-\mathrm{p} / 5 \mathrm{~s}(\mathrm{R} / \mathrm{P} / \mathrm{Y})$ \\
\hline DRC on & $4.0 \times 10^{-4} \mathrm{deg} \mathrm{p}-\mathrm{p} / 5 \mathrm{~s}(\mathrm{R} / \mathrm{P} / \mathrm{Y})$ \\
\hline - Determination (off-line) & $\pm 2.0 \times 10^{-4} \mathrm{deg}(\mathrm{R} / \mathrm{P} / \mathrm{Y})$ \\
\hline - Control Accuracy & $\pm 0.1 \mathrm{deg}(\mathrm{R} / \mathrm{P} / \mathrm{Y})$ \\
\hline
\end{tabular}

*) DRC: Data Relay and Communication

Table 2. Primary characteristics of sensor system.

\begin{tabular}{|c|c|}
\hline Item & Characteristics \\
\hline \multicolumn{2}{|l|}{ PRISM } \\
\hline - Observation Band & 1 band (panchromatic) \\
\hline - Base Height Ratio (B/H) & 1.0 \\
\hline - Spatial Resolution & $2.5 \mathrm{~m}$ at nadir ground $(3.61 \mu \mathrm{rad})$ \\
\hline $\begin{array}{l}\text { - Field of View (FOV), } \\
\text { (Swath Width) }\end{array}$ & $2.9 \mathrm{deg}(35 \mathrm{~km}),(70 \mathrm{~km}$ at nadir $)$ \\
\hline - Pointing Angle & $\pm 1.5 \mathrm{deg}(35 \mathrm{~km}$ at nadir $)$ \\
\hline & $\pm 1.36 \mathrm{deg}(35 \mathrm{~km}$ at fore, aft $)$ \\
\hline - Data Rate & $<960 \mathrm{Mbps}$ \\
\hline \multicolumn{2}{|l|}{ PALSAR } \\
\hline -Frequency, Polarization & L-band, $\mathrm{H}$ and $\mathrm{V}$ polarization \\
\hline -Antenna Type & Active Phased Array \\
\hline \multicolumn{2}{|l|}{-Angle of Incidence } \\
\hline High Resolution Mode & $8-60 \mathrm{deg}$ \\
\hline ScanSAR Mode (5 scaan) & $18-43 \mathrm{deg}$ \\
\hline \multicolumn{2}{|l|}{-Spatial Resolution } \\
\hline High Resolution Mode & $10 \mathrm{~m}$ (2 look, off-nadir $34.3 \mathrm{deg})$ \\
\hline ScanSAR Mode (>5 scan) & $100 \mathrm{~m}$ \\
\hline \multicolumn{2}{|l|}{-Swath Width } \\
\hline High Resolution Mode & $>70 \mathrm{~km}$ \\
\hline ScanSAR Mode (5 scan) & $>350 \mathrm{~km}$ \\
\hline -Data Rate & 240/120Mbps \\
\hline \multicolumn{2}{|l|}{ AVNIR-2 } \\
\hline - Observation Band & 4 bands \\
\hline - Spatial Resolution & $10 \mathrm{~m}(14.28 \mu \mathrm{rad})$ \\
\hline - FOV (Swath Width) & $5.8 \pm 0.1 \mathrm{deg}(>70 \mathrm{~km})$ \\
\hline - Pointing Angle & \pm 44 deg in cross-track \\
\hline - Data Rate & $<160 \mathrm{Mbps}$ \\
\hline
\end{tabular}


sensor telescopes to the Earth.

2) Sensor data compression from 1 Gbps output to 240 Mbps down link capacity. Sensor output data rates are reduced by lossy compression at rate $1 / 4.5$ or $1 / 9$ for PRISM, and lossless compression at rate $3 / 4$ for AVNIR-2, respectively.

3) Mission data transmission at high data rate of $240 \mathrm{Mbps}$ via Data Relay Test Satellite (DRTS) to the ground stations.

4) High density onboard semi-conductor memory for mission data recording and reproducing with capacity of 720 Gbit.

5) High accuracy orbital control to optimize the baseline length between master and slave paths for SAR interferometry.

6) Full and Dual polarization observation mode, wide swath observation of $350 \mathrm{~km}$ by ScanSAR mode as well as fine mode of PALSAR.

7) High accuracy digital elevation model (DEM) extraction with TLS stereoscopic observation with the height accuracy less than $5 \mathrm{~m}$ and the high spatial resolution $2.5 \mathrm{~m}$ compatible with wide swath width $70 \mathrm{~km}$ of PRISM.

8) Onboard high accuracy star tracker and Global Positioning System (GPS) receiver to determine the pixel position with accuracy $10 \mathrm{~m}$ without Ground Control Points (GCPs) and 3m with GCPs useful for the map generation and updating.

9) Pointing ability of AVNIR-2 and PALSAR to observe an arbitrary area worldwide within 2 days on a fine day and 5 days on a cloudy day to realize emergency observations.

10) Simultaneous observation in one position by AVNIR-2 and PALSAR.

\section{Data Characteristics for Information Extraction}

The image interpretation using spatial and the radiometric characteristics of the land surface with topographic information gives us useful interpretation keys to understand condition, status, mechanism of disastrous phenomena, and prospect for the possible coming disasters.

Geo-Hazard and Environmental-Hazard are the two highlights of disasters in recent years. Here are shown examples from Geo-Hazard, 3.1 Volcano, 3.2 Earthquake -induced Landslides, and from Environmental-Hazards, 3.3 Flood and 3.4 Glacier are explored with regard to the usefulness.

\subsection{Volcano Observation}

Sakurajima Volcano is one of the most active volcanoes in Japan, therefore the residents have great concern in the monitoring of its activity in the long history. The pan-sharpened 3D image (Furuta, 20076) ) generated from AVNIR-2 and PRISM with Digital Surface Model (DSM) made from PRISM provides image of Fig.1. Information of potential use is as followings.

(1) Pan-sharpened 3D image provides high resolution,

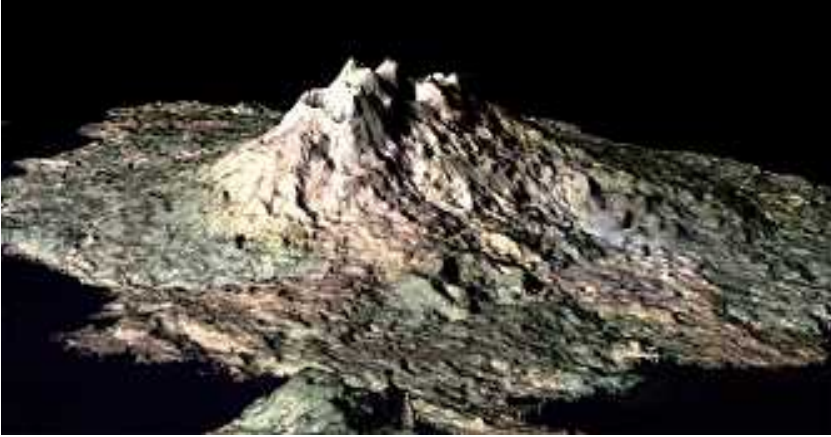

Fig. 1. Sakurajima volcano bird's eye view generated from AVNIR-2 and PRISM (Furuta, 2007)

multi-spectral topography.

(2) Both spectral and textural information works complementally to detect changes.

(3) 3D landscape could be used to observe changes in shape of mountains, steep-sided extrusion of viscous lava, greening to prevent debris flow, and to gain an insight into the anticipated lava or pyroclastic flows.

The image of Fig.1 indicates the geographic information of historical volcanic activity of major eruptions and the accompanied lava floors which are shown as yellowish and brownish colored surfaces from top to the foot of the mountain penetrating into green colored vegetated area. The surface roughness also provides information about the lava floors.

ALOS is the unique satellite provides us topography or physiognomy of mountain with widely extending foot of a mountain. The combined use of the traditional geographic maps in high accuracy connoting information of long historical events and the up-to-date satellite image has become available, which has improving our knowledge to interpret the characteristics of the volcanoes.

\subsection{Earthquake-induced Landslide Observation}

There were earthquake-induced landslides in the Noto Peninsula on March 25, 2007. As in this case, for the detection of landslides spread over the large area, pan-sharpened images of spatial resolution $2.5 \mathrm{~m}$ generated from AVNIR-2 and PRISM is useful. Information of potential use is as followings.

(1) Using two pan-sharpened images of before and after the earthquake, blocked roads by slope failure are detectable as shown in Fig. 2.

(2) The change detection provides information of possible hazards to moving traffics, for evacuation and relief works.

The image processing for change detection is suitable for the quick response to the requirement of early information for the local measurement immediately after the disaster occurrences.

ALOS is good at producing time series data sets to record the land at the moment and the up-to-date archive in every cycle of observation. They are very accurately 

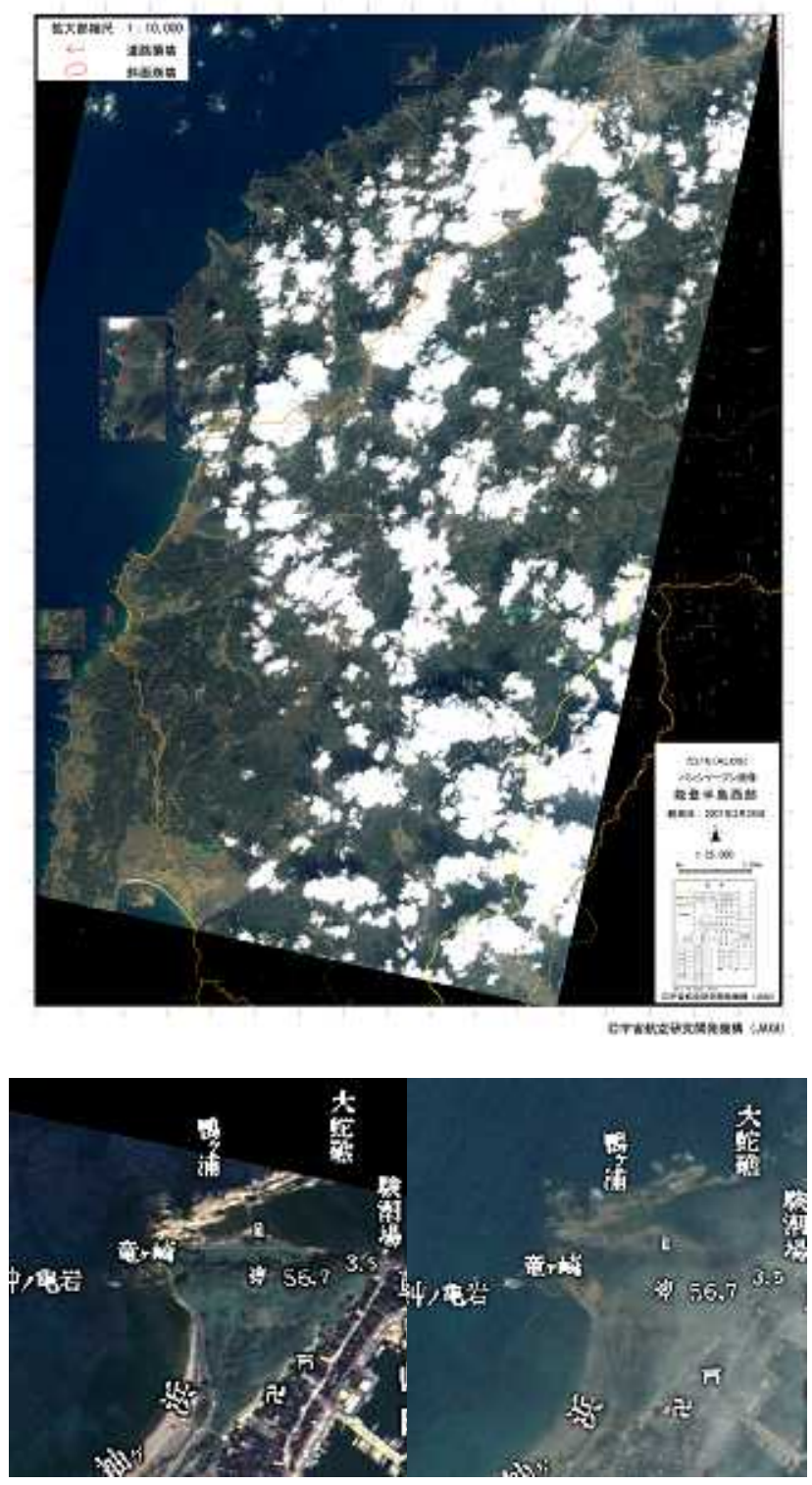

Fig. 2. Landslide in the Noto Peninsula observed using multi-temporal pan-sharpened image data sets of PRISM and AVNIR-2 (JAXA/RESTEC, Furuta, 2007)

overlaid onto the traditional highly accurate maps that are produced complying the national standard. Among earth observation satellites available for the general users, ALOS has the highest performance in geographic mapping in a scale of $35-70 \mathrm{~km}$ wide to capture all in one observation image which is the necessary condition to detect widely distributed damaged spots induced by the earthquakes or heavy rainfalls in a large scale.

However sensors were calibrated and standard products were validated, with some points to be improved (Shimada $^{7}$, Tadon et al. ${ }^{8}$, 2007), i.e. radiometric image quality of PRISM affecting the geometric accuracy as not exercising its inherent ability (Guren et al., 20079) $)$. There were discussions on the quantized Digital Number (DN) in 8 bits, and the noise due to the data compression for the transmission.

For those indications, improvements in processing

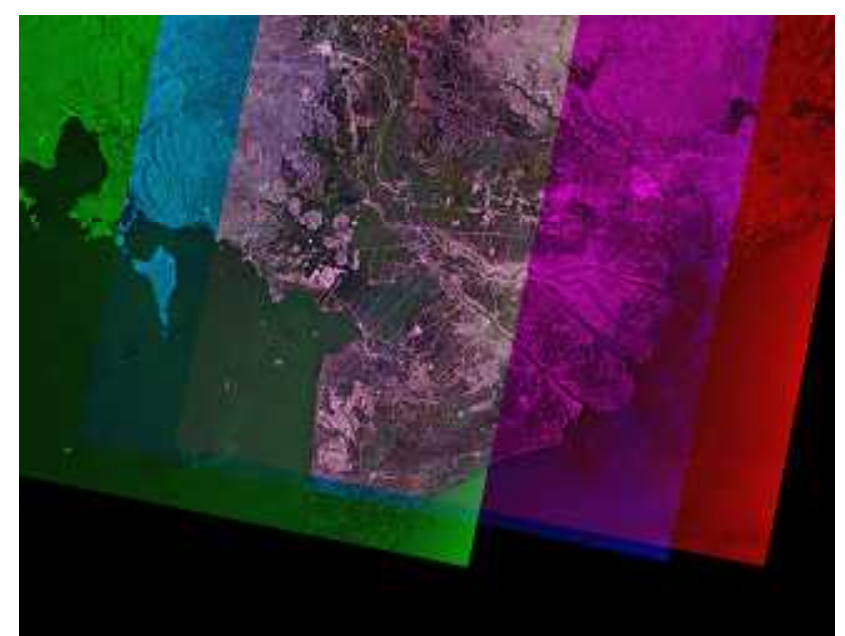

Fig. 3. Flood of Mekong River observed by PALSAR (JAXA/RESTEC, Furuta, 2007)

system of data product were applied to the latest data production in Japan Aerospace Exploration Agency (JAXA)/Earth Observation Center (EOC). Therefore the latest ALOS data is available for the map generation and the updating, although further improvement is expected for the next generation.

\subsection{Flood Observation}

The swath width of PALSAR in ScanSAR mode is wide enough to cover flood area of large rivers like Mekong River flowing across the Indochina Peninsula of which the color composite image is shown in Fig. 3. Information of potential use is as followings.

(1) Multi-temporal observation provides the color composite image assigning three observation images acquired on different days of September 27, October 2 and October 14 in 2006 to Red, Green and Blue respectively, to delineate inundated area and estimate their duration in the period.

(2) PALSAR is highly sensitive to detect bank rip, burst in the dike.

(3) Geometrically corrected image is useful to estimate change in width of a river, with station in-situ data.

The color composite image indicates the inundation area by the darken color of the pixel which have color mixing Red, Green, Blue (RGB) corresponding to the observation date.

The ScanSAR mode observations were considered as suitable to the case of large spatial and temporal scale flood extending wide and moving relatively slow from upstream to downstream as frequently observed in river basins in continental scale. However in Japan this method could be used in case of large area inundation, higher spatial resolution will be required for the most cases.

\subsection{Glacier Observation}

The images of ALOS/AVNIR-2 in Fig.4 indicate the change of glacier in the Southern Alps, South Island of New Zealand. The left image is a scene on August 28, 2006, and the right image is a scene on August 14, 2007, 


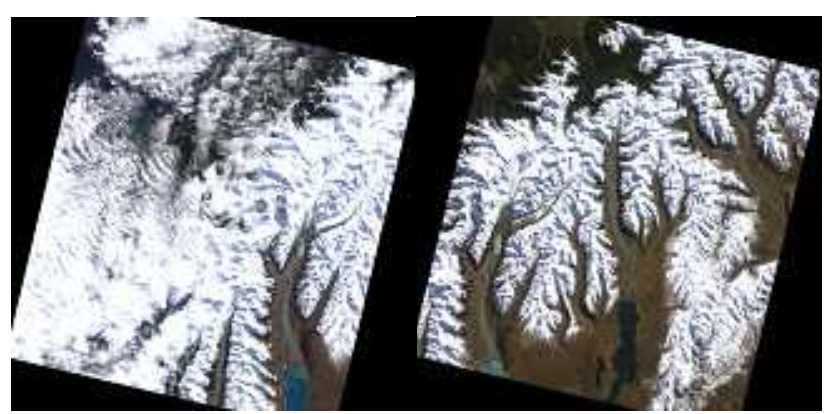

Fig. 4. The glaciers in the Southern Alps, South Island of New Zealand observed by ALOS (Left: August 28, 2006, Right: August 14, 2007, JAXA/RESTEC, Sugimura, 2008)

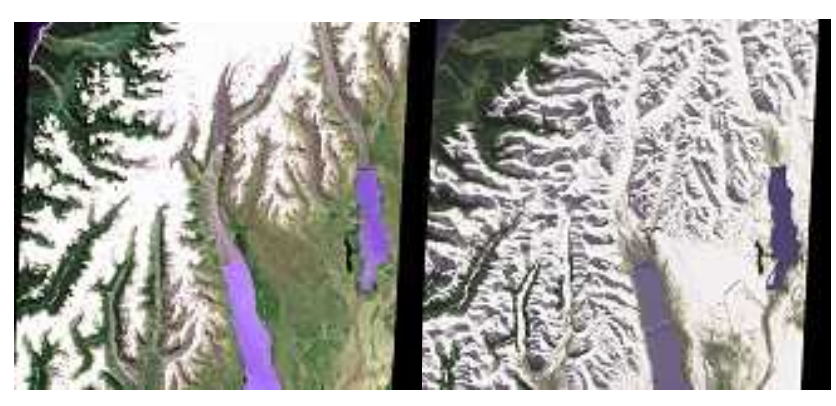

Fig.5. Glacier observation by JERS-1/OPS (Left: December 12, 1994, Right: July 30, 1995, JAXA/RESTEC, Sugimura, 2008)

where snow and ice covered mountains, fields and valleys are seen as white, and the water flows from the glacier make rivers and lakes downstream.

The images of JERS-1/OPS in Fig. 5 are archived data obtained 12 years before the ALOS images in Fig. 4. The left is a scene of the beginning of summer in 1994, where the snow line rise and the glacier thawing are indicated in the image. The right image is a scene of the winter in 1995, 7 months later than the date of former image observed, the snow and ice cover all the mountain and basin area except the vegetated lowland along the west coast seen at the upper left of the image. The area of glacial lake in 1994, 1995 are relatively smaller than that in 2007. These multi-temporal data sets are precious historical data to understand the change of the glacier inventory.

However the glacier is a reservoir of fresh water which is a source of water supply for us and ecosystems and hydrological power plants, sometime they could cause Glacial Lake Outburst Flood (GLOF), when the snow and ice thawing advanced.

For the purpose of long term monitoring of the glacial retreat and advance, JERS-1 data sets from 1992 to 98 and ALOS data sets from 2006 to the present will contribute to the worldwide inventory of glaciers.

\section{Integration of Remote Sensing Data with GIS}

The integration of remote sensing data with Geographic
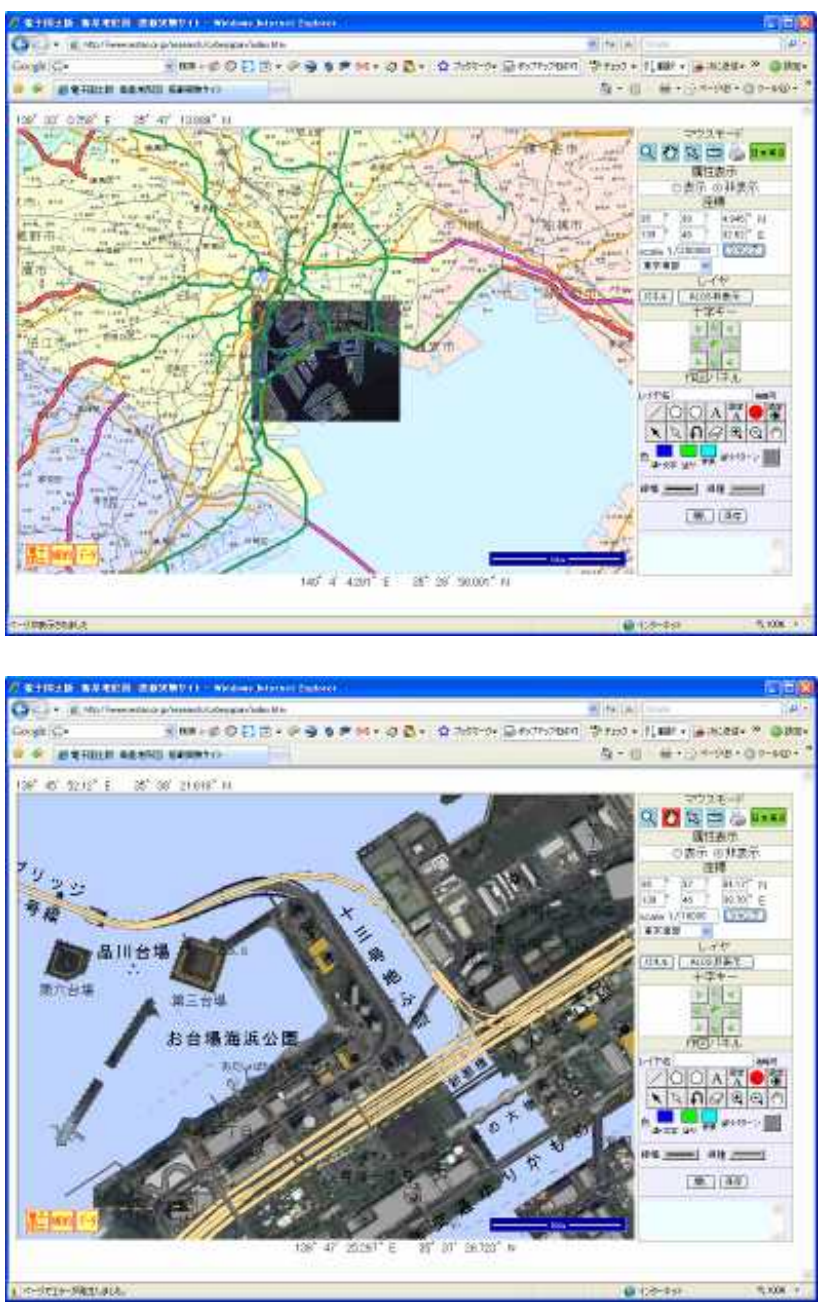

Fig. 6. A trial product of pan-sharpened image integrated on a map of South of Tokyo, Japan in GSI CYBERJAPAN (JAXA/RESTEC, Furuta, 2007)

Information System (GIS) is one of ubiquitous systems to provide information for the direct widely distributed local users, and their applications for and convenient use by disaster information system is a great concern.

\subsection{Role of GIS}

The integration of remote sensing data with GIS such as Geographical Survey Institute (GSI) / CYBERJAPAN as a nationwide system, WebGIS as local and regional systems for on-line data dissemination, and Google Earth as a worldwide system are expected for information interpretation, translation, communication, and facilitating user uptake for individual applications.

\subsection{Example of Integration}

As a trial integration of ALOS pan-sharpened image and a WebGIS, GSI CYBERJAPAN, the map of South of Tokyo Japan is demonstrated as shown in Fig.6. On the ALOS image in a proper dimension as the back-ground, necessary geographic information are overlaid.

\section{Conclusions}

ALOS data applicability was discussed reviewing some early case studies, while the operation of ALOS is in the 
middle of continuing further R\&D, validation and demonstration of the data products and the system for data distribution for users, the disaster applications featuring ALOS capacity is considered as the effective system on the disaster strikes and on the preparations for the coming disasters.

ALOS program is a great challenge in the world to take the informative satellite-based earth observation system to the normative system in the disaster monitoring, through practical exercises applying data to the actual disasters and participating in the disaster-preparedness drills.

The advantages gained by introducing ALOS data over the observation in the actual disasters or in the drills;

1) Data Fusion such as 4-band spectral high spatial resolution $2.5 \mathrm{~m}$ pan-sharpened image, and combined use of optical sensors and SAR image.

2) Stepping up of the spatial dimension in geographic mapping of Earth from 2D to 3D.

3) Compatibility of systematic and interruptible urgent observation.

4) Agility of AVNIR-2 with pointing mechanism and the minimum specifications of imaging good enough for disaster monitoring.

Expected improvements for the next generation satellites;

1) Higher revisit frequency.

2) Spatial resolution about $1-5 \mathrm{~m}$.

There are some possible concepts to meet these improvements. In any case, trade-off study among the requirements and the resources are necessary.

In the system development, data handling with wall to wall consistency through out the measurement data to the output information, using sensors, onboard data recorders, data transmission, receiving, recording, processing, and data retrieval and archive systems.

In operation, we need strategy to realize the optimal user requirements in general.

To build operational systems for disaster monitoring, newly developed satellite-based information product systems and the present systems should be complementally and synergistically integrated, not necessarily substituted mutually.

\section{References}

1) Kishi, S. Ohkura, H. and Akutsu, T.: Computer Mapping of Flooded Area Detected from Landsat TM Data, J. of The Remote Sensing Soc. of Jpn., 6. 4 (1986), pp.21-26 (in Japanese).

2) Rattakul, B.: Evolving Trends in Geophysical, Oceanic and Atmospheric Phenomena - Implications for Disaster Risk Reduction, AOGS $4^{\text {th }}$ Annual Meeting, (2007), p.18.

3) Gupta, H.: Natural and Human Induced Environmental Hazards \& Disasters, AOGS $4^{\text {th }}$ Annual Meeting, (2007), p.26.

4) ICSU Planning Group: A Research Plan for Integrated Research on Disaster Risk - addressing the challenge of natural and human-induced environmental hazards, ICSU (2008), pp.1-89.

5) Osawa, Y. Toda K. Wakabayashi H. Hamazaki T. and Igarashi T.: Japan's Land Observation Satellite Programs and Advanced Land Observing Satellite (ALOS), Land Satellite Information in the Next Decade, Conference Proc. (1995), pp.I-25-I-30.

6) Furuta, R.: Characteristic Data Applications of ALOS, J. of Jpn. Soc. of Photogrammetry and Remote Sensing, 46. 3 (2007), pp.27-29 (in Japanese).

7) Shimada, M.: Calibration and Validation of ALOS and Calibration of PALSAR, J. of Jpn. Soc. of Photogrammetry and Remote Sensing, 46. 1 (2007), pp.5-11 (in Japanese).

8) Tadono, T. Shimada, M. Hashimoto, T. Takaku, J. Mukaida, A.: On the Calibration of PRISM, AVNIR-2 and the Early Validation of PRISM/DSM, J. of Jpn. Soc. of Photogrammetry and Remote Sensing, 46. 1 (2007), pp.12-16 (in Japanese).

9) Guren, A. Kocaman, S. Wolff K.: Calibration and Validation of Early ALOS/PRISM Images, J. of Jpn. Soc. of Photogrammetry and Remote Sensing, 46. 1 (2007), pp.24-38. 